\title{
O LUGAR SISTEMÁTICO DA DOUTRINA DO DIREITO NA OBRA DE ARTHUR SCHOPENHAUER
}

\author{
Felipe dos Santos Durante*
}

\begin{abstract}
Resumo: Este artigo tem como objetivo delimitar o lugar sistemático da doutrina do direito no sistema filosófico de Arthur Schopenhauer. A partir da explanação do conceito de egoísmo (Egoismus), será derivado o conceito de injustiça (Unrecht) e, pela sua negação, o conceito de justiça (Recht). A partir dos conceitos de injustiça e de justiça a doutrina do direito poderá ser exposta e também o seu lugar sistemático.

Palavras-chave: Ética; Justiça Temporal; Doutrina do Direito; Estado; Arthur Schopenhauer.
\end{abstract}

Abstract: This article aims to show the systematic place of philosophy of right in Arthur Schopenhauer's own philosophical system. This place will be demonstrated from the explanation of the concept of egoism (Egoismus), the concept of wrong (Unrecht) and his negation, the concept of justice (Recht). Finally, the philosophy of right and his systematic place in the philosophical system will be elucidated.

Keywords: Ethics; Temporal Justice; Doctrine of Right; State; Arthur Schopenhauer.

* Doutorando em Filosofia no Instituto de Filosofia e Ciências Humanas (IFCH) da Universidade Estadual de Campinas (UNICAMP) - Campinas, São Paulo, Brasil. Bolsista FAPESP. E-mail: xfelipedurantex@gmail.com. 


\section{A Doutrina do Direito (Rechtslehre) ou Justiça Temporal (zeitliche Gerechtigkeit)}

É possível notar, ao longo da obra schopenhaueriana a utilização do conceito de Justiça (Gerechtigkeit) em três registros: (i) a Justiça como Virtude (freiwillige Gerechtigkeit), ${ }^{1}$ (ii) como Justiça Temporal (zeitliche Gerechtigkeit), e (iii) como Justiça Eterna (ewige Gerechtigkeit). A primeira ocorrência para o uso da Justiça pode ser entendida como um certo grau no desvelar o Véu de Maia, um certo olhar através do princípio de individuação que faz com que o indivíduo abdique em parte de seu egoísmo, fazendo menor distinção entre si mesmo e os outros. O segundo tipo de justiça afirma-se como tal quando a ação realizada para evitar uma ação injusta refere-se ao futuro (Zukunft); ela tem no Estado seu dispositivo, seu meio para efetivar-se, podendo, assim, retaliar e punir. Por fim, a justiça eterna rege o mundo. O segundo tipo de justiça, a justiça temporal, é aquele pelo qual se interessa o nosso trabalho e será objeto de análise desse texto.

O mundo como representação é a manifestação de uma essência una e indivisa, a vontade. Todos os problemas inerentes à metafísica dos costumes ${ }^{2}$ têm como fonte a afirmação e a negação

\footnotetext{
${ }^{1}$ Essa distinção é bem notada por Annette Godart-van der Kroon no seu artigo Schopenhauer's Theory of Justice and its Implication to Natural Law. Contudo, os tradutores de língua portuguesa não chegaram a um consenso sobre a melhor tradução para o termo freiwillige Gerechtigkeit. Alguns traduzem por justiça espontânea, outros por justiça livre, outros, ainda, por justiça voluntária. Utilizaremos o termo de justiça voluntária, mas tendo em mente que esse tipo de justiça se refere à justiça enquanto virtude cardinal.

${ }^{2}$ Nas preleções de Berlim, os objetivos da ética são esclarecidos pelo então professor Schopenhauer: cabe a ela mostrar que (i) não existe nenhuma doutrina do dever, que (ii) não existe nenhum princípio ético universal, e que (iii) não existe um dever incondicionado. Em suma, o ponto de partida da ética schopenhaueriana já delineia um horizonte necessariamente antikantiano. Concomitantemente com esses três objetivos, a ética trata, necessariamente, de dois problemas capitais: (i) a liberdade e a sua relação com a necessidade, e (ii) o significado ético da conduta humana, i.e., o fundamento da moral . Nesse
} 
da vontade de viver, cujos graus constituem o núcleo, a base, e a qualidade de todo comportamento imoral, amoral e moral. A afirmação da vontade de viver manifesta no plano fenomênico dá origem ao egoísmo, que, como sabido, é a motivação amoral predominante dos indivíduos. Isso significa que, por sermos todos fenômenos de uma vontade única que luta contra si mesma na pluralidade do mundo como representação, acabamos por instaurar relações antimorais entre os indivíduos. E não é a instrução nem a reflexão, i.e., não é de forma racional que se alcança a moralidade, pois, como sabido, o querer não pode ser ensinado (velle non discitur) (SCHOPENHAUER, 2005: §55, 381; SCHOPENHAUER, 1911-1942: §55, I 347).

\section{O Egoísmo, o Conflito Interno da Vontade e a Guerra de Todos contra Todos}

Schopenhauer justifica a hostilidade entre os indivíduos a partir de duas perspectivas: (i) a perspectiva ética, ao mostrar que cada um quer tudo pra si, o egoísmo prático, e (ii) a perspectiva epistemológica, ao mostrar que o sujeito do conhecimento é o sustentáculo do mundo, o egoísmo teórico.

Em O Mundo como Vontade e Representação, Schopenhauer recorda um aspecto de sua filosofia que fora explicado tno segundo livro dessa sua obra magna, ao mesmo tempo em que enuncia a análise do egoísmo como forma de entender a luta contínua entre os indivíduos, como forma de entender a guerra de todos contra todos:

ponto é possível diferenciar o que Schopenhauer entende por ética - o conjunto de objetivos e problemas supracitados - e o que ele entende por metafísica dos costumes - que seria um conceito mais abrangente que o de ética e incluiria em seu conteúdo programático toda a filosofia moral, afirmação e negação da vontade de viver, inclusive a doutrina da redenção. 
Recordemos do livro segundo que na natureza inteira, em todos os graus de objetivação da Vontade, existe necessariamente uma luta contínua entre os indivíduos de todas as espécies, e, justamente aí, exprime-se um conflito interno da Vontade de vida consigo mesma. Nos graus mais elevados de sua objetivação, como qualquer outra coisa, esse fenômeno se expõe em distinção mais acentuada e, por conseguinte, pode ser mais bem decifrado. Tendo em vista esse fim, queremos primeiro perquirir em sua fonte o EGOÍSMO, como ponto de partida de toda luta. (SCHOPENHAUER, 2005: §61, 425-426; SCHOPENHAUER, 1911-1942: §61, I 391. Grifos no original). ${ }^{3}$

Entre os seres dotados de entendimento, os animais e os homens, o egoísmo é tido como a motivação fundamental, porque ele pode ser entendido como um ímpeto para existência - uma existência desejada incondicionalmente - e para o bem-estar, o que o identifica com a afirmação da vontade de vida.

Apenas no tempo e no espaço há pluralidade, uma vez que o princípio de individuação torna plural - fragmentado e dividido - o que em-si é uno e indiviso: a vontade aparece em toda parte na multiplicidade de indivíduos, não como coisa-em-si, mas como fenômeno. O princípio de individuação permite que a vontade se manifeste de igual modo em número infinito de fenômenos de maneira plena e íntegra. O grau mais elevado de objetivação alcançado pela vontade é o homem, e é no homem que o egoísmo pode se manifestar de forma plena. $O$ indivíduo é o sujeito cognoscente, e, enquanto tal, é o portador da totalidade do mundo

\footnotetext{
${ }^{3}$ No original: ,Wir erinnern uns aus dem zweiten Buch, daß in der ganzen Natur, auf allen Stufen der Objektivation des Willens, nothwendig ein beständiger Kampf zwischen den Individuen aller Gattungen war, und eben dadurch sich ein innerer Widerstreit des Willens zum Leben gegen sich selbst ausdrückte. Auf der höchsten Stufe der Objektivation wird, wie alles Andere, auch jenes Phänomen sich in erhöhter Deutlichkeit darstellen und sich daher weiter entziffern lassen. Zu diesem Zweck wollen wir zunächst dem Egoismus, als dem Ausgangspunkt alles Kampfes, in seiner Quelle nachspüren“.
} 
objetivo, ou seja, o indivíduo acaba por se considerar o centro do mundo, como possuidor e mantenedor de toda realidade; toda a natureza e todos os indivíduos externos a ele não existem senão em virtude de sua representação. Dessa forma, nada pode ser mais importante para ele do que ele mesmo.

Contudo, Schopenhauer não considera o egoísmo uma conduta estritamente má; antes, deve-se entendê-lo como uma conduta moral indiferente, ${ }^{4}$ uma espécie de destino inescapável, um ponto de vista natural, não sendo nem bom nem mau, mas um atributo predominante e recorrente dos indivíduos. O egoísmo nada mais é do que o desejo de ser e continuar sendo. Exatamente aquilo que é a afirmação da vontade. O ser egoísta busca continuar existindo e, se possível, em melhor situação; ele é aquele que considera a afirmação de si fundamental, querendo conservar o seu próprio eu nas melhores condições possíveis. Se for preciso, pode até prejudicar o outro, mas prejudicar o outro não é para o egoísta um fim em si mesmo: é apenas um meio para obter o seu fim.

Enquanto cada homem busca avidamente assegurar sua existência nas melhores condições possíveis, perseguindo seus fins pelos meios que julga adequado, certamente os meios de realização do seu querer entrarão em conflito com o querer e os meios de realização do querer de outro indivíduo. Tem-se, assim, uma sobreposição das esferas de afirmação da vontade dos indivíduos, i.e., a concorrência, e a colisão de interesses. Dessa forma, o ser egoísta é responsável pelo conflito interno da vontade conseguir atingir temível manifestação no mundo como representação, engendrando a luta entre os indivíduos, a guerra de todos contra todos.

\footnotetext{
${ }^{4}$ Segundo Schopenhauer, o egoísmo produz ações moralmente indiferentes. Cf. SCHOPENHAUER, 2001b: §16, 138; SCHOPENHAUER, 1911-1942: §16, III 680). Egoísmo e valor moral excluem-se um ao outro.
} 
$\mid 180$ |

O Lugar Sistematico da Doutrina...

\section{A Relação do Egoísmo com a Injustiça e o Injusto}

As conexões que Schopenhauer traça entre egoísmo e injustiça indicam que o egoísmo não é somente uma motivação indiferente ou neutra, mas está necessariamente conectado com a origem da guerra de todos contra todos. Schopenhauer escreve:

Já examinamos a primeira e a mais simples afirmação da Vontade de vida, a simples afirmação do próprio corpo, vale dizer, a exposição da Vontade via atos no tempo, na medida em que o corpo, em sua forma e finalidade, expõe essa mesma Vontade espacialmente, e não mais. Semelhante afirmação se mostra como conservação do corpo por meio do emprego de suas forças. (SCHOPENHAUER, 2005: §62, 428; SCHOPENHAUER, 1911-1942: §62, I 393-394). ${ }^{5}$

E, no sentido do egoísmo consistir na afirmação do próprio corpo, Schopenhauer completa:

- Ora, na medida em que a Vontade expõe aquela AUTOAFIRMAÇÃO do próprio corpo em inumeráveis indivíduos, um ao lado do outro, essa autoafirmação, em virtude do egoísmo inerente a todos, vai muito facilmente além de si mesma até a NEGAÇÃO da mesma Vontade que aparece em outro indivíduo. (SCHOPENHAUER, 2005: §62, 429; SCHOPENHAUER, 1911-1942: §62, I 394. Grifos no original). ${ }^{6}$

\footnotetext{
${ }^{5}$ No original: „Es ist bereits auseinandergesetzt, daß die erste und einfache Bejahung des Willens zum Leben nur Bejahung des eigenen Leibes ist, d.h. Darstellung des Willens durch Akte in der Zeit, in so weit schon der Leib, in seiner Form und Zweckmäßigkeit, denselben Willen räumlich darstellt, und nicht weiter. Diese Bejahung zeigt sich als Erhaltung des Leibes, mittelst Anwendung der eigenen Kräfte desselben“.

${ }^{6}$ No original: „,- Indem nun aber der Wille jene Selbstbejahung des eigenen Leibes in unzähligen Individuen neben einander darstellt, geht er, vermöge des Allen eigenthümlichen Egoismus, sehr leicht in einem Individuo über
} 
Para Schopenhauer, o egoísmo leva à invasão dos limites da afirmação da vontade alheia. Essa invasão pode ocorrer por (i) ferimento / dano / lesão (Verletzung), (ii) por destruição do corpo de outrem ou (iii) quando ocorre a imposição de uma vontade particular a uma vontade alheia - que é negada e passa, então, a servir à vontade impositiva, ${ }^{7}$ e pode afetar a pessoa (Person), a liberdade (Freiheit), a propriedade (Eigentum), e a honra (Ehre). ${ }^{8}$ Essa afirmação da vontade para além do próprio corpo, mediante a negação da vontade de outrem, é definida por Schopenhauer como injustiça (Unrecht).

Quem sofre injustiça - quem tem a vontade negada por uma vontade estranha - sente esta invasão na esfera de afirmação do próprio corpo - a primeira e mais básica afirmação da vontade de viver. Mas é importante ressaltar que em uma certa perspectiva o praticante da injustiça também está sendo injusto consigo mesmo, uma vez que a vontade dele e a vontade da vítima são, em essência metafísica, a mesma vontade: vítima e carrasco são uma só e

diese Bejahung hinaus, bis zur Verneinung desselben, im andern Individuo erscheinenden Willens".

${ }^{7}$ Cf. SCHOPENHAUER, 2005: §62, 429; SCHOPENHAUER, 1911-1942: §62, I 394 .

${ }^{8}$ Aqui temos uma pequena discrepância entre formulações: somente no escrito SFM, do ano de 1840, Schopenhauer inclui a invasão dos limites da afirmação da vontade que correspondem à liberdade como uma das possibilidades de ocorrência da injustiça. (Cf. SCHOPENHAUER, 2001b: §17, 150-151; SCHOPENHAUER, 1911-1942: §17, III 689-690). Na formulação elaborada em Parerga e Paralipomena, datada do ano de 1851, a liberdade não é mencionada como uma categoria passível de ser afetada de forma a ser configurada uma injustiça. (Cf. SCHOPENHAUER, 2000, Capítulo 9 - Sobre a doutrina do direito e a política, §121, 241; SCHOPENHAUER, 1911-1942, Kapitel 9 - Zur Rechtslehre und Politik, §121, V 264). Em última instância, o ataque à pessoa, à liberdade, à propriedade e à honra parecem se configurar como ataques à esfera de afirmação da vontade do indivíduo. Como parece estranho, a partir dessa perspectiva de interpretação do conceito, desconsiderar um elemento tão importante como a liberdade, decidiu-se por manter a formulação feita em Sobre o Fundamento da Moral por considerá-la a mais completa. 
mesma coisa; é a vontade dilacerando-se; é a vontade cravando os dentes na própria carne. O carrasco (praticante da injustiça) apreende isso através de um sentimento de difícil compreensão e explicação, a saber, o remorso (Gewissensbiß) ou injustiça cometida (ausgeübten Unrechts).

O sentimento de remorso é uma espécie de confissão involuntária do praticante da injustiça do seu ato; um sentimento turvo de que aquilo que está sendo considerado como diferença, devido ao princípio de individuação, é, no fundo, identidade; trata-se do conhecimento turvo do fato de que a injustiça praticada é cometida contra si mesmo; é o conhecimento, ainda que confuso, do fato de que a vontade crava os dentes na própria vontade.

Por mais que o indivíduo esteja envolto no princípio de individuação, segundo Schopenhauer, no mais íntimo de sua consciência o indivíduo tem o pressentimento de que o mundo empírico é mero fenômeno, aparência. ${ }^{9}$ Quem pratica a injustiça sente que quem sofre a injustiça é igual a ele em essência, sente que o outro e ele são ambos um esforço de autoconservação, e que ele, o praticante da injustiça, nesse caso, é mais forte.

Esse sentimento do injusto é a consciência moral (Gewissen), que também é conhecida por foro íntimo e por tribunal interno, e é justamente a tomada de consciência do sentido ético da ação praticada pelo indivíduo pelo próprio indivíduo: "o saber do homem sobre aquilo que fez" (SCHOPENHAUER, 2001b: §8, 87; SCHOPENHAUER, 1911-1942: §8, III 640.); ${ }^{10}$ pode ser

${ }^{9}$ Cf. SCHOPENHAUER, 2005: §65, 465; SCHOPENHAUER, 1911-1942: §65, I 431.

${ }^{10}$ No original alemão: “Es ist das Wissen des Menschen um Das, was er gethan hat". Sobre a consciência moral ser a tomada de consciência do sentido ético da ação, pode-se ler em: "Mas, a partir de nossa exposição não mítica porém filosófica da justiça eterna, queremos agora passar à consideração que lhe é aparentada do significado ético da ação e consciência moral, que não passa do mero conhecimento sentido desse significado" (SCHOPENHAUER, 2005: §64, 456; SCHOPENHAUER, 1911-1942: §64, I 422). No original alemão: “Aber von unserer nicht mythischen, sondern philosophischen Darstellung der ewigen Gerechtigkeit wollen wir jetzt zu den dieser verwandten Betrachtungen der 
entendida como um tipo de conhecimento (Erkenntnis), porém um conhecimento não teórico, um conhecimento sentido, uma espécie de sentimento, podendo ser entendida como a expressão emocional sensível do conhecimento que temos do significado moral de nossas ações.

O enfoque dado pela consciência moral à ação refere-se ao seu significado interno. Para aquele que cometeu a ação injusta ela significa uma censura moral que indica a veemência da concreção do egoísmo em um corpo que invadiu os limites de afirmação da vontade de outro corpo.

A partir da exposição do conceito de injustiça e da argumentação desenvolvida, é possível afirmar que tal conceito aparece com precedência ontológica frente ao conceito de justiça. Isso significa que a injustiça é um conceito originário e positivo, e isso porque ela é sentida imediatamente, manifestando-se por si mesma, sendo natural e fundamentada na experiência. ${ }^{11}$ Ela também é a condição de inteligibilidade do conceito de justiça (Recht).

O estabelecimento dos limites existentes entre afirmar a própria vontade e o negar a vontade de outrem fornece, em referência a uma simples e pura determinação moral, todo o domínio das possíveis ações injustas ou justas:

Na escala dos distintos graus de força com que se manifesta a vontade de viver no indivíduo humano, os conceitos de justiça e injustiça constituem um ponto fixo (como o ponto de congelamento dos termômetros), a saber, o ponto onde a afirmação da própria vontade se torna negação da vontade alheia, isto é, o ponto no qual a vontade revela o grau de sua intensidade e, igualmente, o grau de confusão do

\footnotetext{
ethischen Bedeutsamkeit des Handelns und des Gewissens, welches die bloß gefühlte Erkenntniß jener ist, fortschreiten".

${ }^{11}$ Cf. SCHOPENHAUER, 2001b: §16, 138-139; SCHOPENHAUER, 1911-1941: §16, III 680-681. Grifo nosso; Cf. SCHOPENHAUER, 1911-1942: §62, P. 434, I 399.
} 
conhecimento imerso no principium individuationis, através do agir injusto. (SCHOPENHAUER, 2001a: 101; SCHOPENHAUER, 1911-1942: X 162. Grifos no original) ${ }^{12}$

Estes dois termos - injustiça e justiça - podem ser considerados determinações morais, uma vez que se referem à conduta humana enquanto tal, ao valor dessa conduta, à íntima significação dessa conduta em si (die innere Bedeutung dieses Handelns an sich). ${ }^{13} \mathrm{O}$ significado íntimo de cada ação da conduta humana em si demonstra-se claramente à consciência moral pelo fato de (i) a prática da injustiça ser acompanhada de uma dor interior (einem inneren Schmerz) e (ii) do praticante da injustiça, enquanto fenômeno, ser diferente de quem a sofre, mas em-si em essência metafísica -, idêntico ao sofredor. Para quem sofre a injustiça, essa significação se expressa no fato (iii) deste sofredor estar dolorosamente consciente da negação de sua vontade e que, (iv) sem praticar injustiça, ele pode se defender de todas as maneiras daquela negação imposta, caso lhe seja possível. Segundo Schopenhauer, "qualquer selvagem saberia reconhecer o justo e o injusto", (SCHOPENHAUER, 2001a: 102; SCHOPENHAUER, 1911-1942: X 163) $)^{14}$ por meio da sensação de aprovação ou desaprovação despertada no observador, ou por meio da sensação de remorso ou de injustiça cometida pelos envolvidos na ação.

\footnotetext{
${ }^{12}$ No original alemão: “Nämlich auf der Skala der höchst verschiedenen Grade der Stärke mit welchen der Wille zum Leben in menschlichen Individuen sich offenbart, sind die Begriffe Recht und Unrecht in fester Punkt (wie der Eispunkt auf dem Thermometer), nämlich der Punkt, wo die Bejahung des eigenen Willens zur Verneinung des fremden wird: d. h. auf diesem Punkt giebt der Wille den Grad seiner Heftigkeit, und zugleich den Grad der Befangenheit der Erkenntniß im principio individuationis an, durch UnrechtThun".

${ }^{13}$ Cf. SCHOPENHAUER, 2005: §62, 436; SCHOPENHAUER, 1911-1942: §62, I 402.

${ }^{14}$ No original alemão: „Alle Wilde nämlich kennen Recht und Unrecht”.
} 
Por serem determinações morais, os direitos derivados dos conceitos de injusto e de justo podem ser denominados naturais, no sentido de que não estão definidos por convenções humanas nem são instituídos pelo Estado, mas existem de maneira inata valem por si e em si -, e são universais e imutáveis - pois valem para todos os indivíduos, em qualquer localidade, e em qualquer época. Assim, o direito natural (Naturrecht) é estabelecido por Schopenhauer como direito moral (moralisches Recht). Dessa forma, a argumentação schopenhaueriana constrói no seio da moral o seu conceito de direito, subsumindo-o ao conceito de moral, e subvertendo a tradição que remonta a Christian Thomasius e, principalmente, Kant. ${ }^{15}$

Apesar dos conceitos de justiça e injustiça serem de fato válidos para o estado de natureza, e o direito moral deles derivado também o ser, a validade do direito moral não se dá em todos os casos para cada indivíduo, permanecendo latente - um direito que não se efetiva -, e, assim, não é eficaz no sentido de impedir que a violência impere. Justo e injusto valem ali apenas como conceitos morais para o autoconhecimento, para a consciência moral (Gewissen) de cada um.

Assim, pode-se afirmar que a doutrina moral do direito se refere à parte ativa da dinâmica de esferas de afirmação da vontade no mundo considerado pela faceta da representação, o agir (Tun), não à parte passiva, a forma pela qual as vontades são afetadas, o sofrer (Leiden). Esse só é considerado pela moral de maneira indireta, a saber, tendo em vista provar que as medidas tomadas com a finalidade de evitar o sofrimento de uma injustiça de modo algum sejam consideradas e confundidas com a prática da injustiça.

\footnotetext{
${ }^{15}$ Christian Thomasius (1655-1728) foi um dos primeiros pensadores a retirar o direito da esfera da moral e da ética. (Cf. FASSÒ, 1979, 170). Kant também opera com essa distinção, o que é motivo de duras críticas provenientes de Schopenhauer ao filósofo de Königsberg Deve-se atentar para o fato de que toda argumentação schopenhaueriana, no que tange à fundamentação da doutrina do direito, é um esforço em subsumir o conceito de direito, novamente, à esfera da ética e da moral.
} 


\section{O Papel Sistemático da Doutrina do Direito na Obra Schopenhaueriana}

O homem, por ser um organismo mais complexo, possui necessidades mais complexas: a partir da complexidade do corpo humano e da complexidade de consciência humana (a razão), o homem pode refletir acerca da sua situação de penúria no estado de natureza e pode procurar soluções para superá-la. Pelo cálculo da razão o Estado é concebido, e pelo contrato social ele é instituído. Não se trata de uma vinculação a uma concepção utilitarista, visando o bem como finalidade, pois o bem não é a finalidade do Estado; evitar o injusto, instaurando a ordem social é o modo pelo qual se tornou possível vencer o egoísmo animal destrutivo. Mas essa vitória não é um ultrapassamento mesmo do egoísmo, é apenas a limitação egoísta do egoísmo.

A justiça temporal tem sua sede no Estado, e a doutrina do Estado refere-se, enquanto conjunto dos dispositivos institucionais e normativos de combate aos atos injustos, à pura doutrina do direito, que tem no justo e no injusto por natureza seu padrão objetivo de medida; e o justo e o injusto referem-se aos limites da afirmação da vontade de viver. Essa forma de conceber o Estado faz com que essa instituição não possua nenhum status moral nem função ética, diferindo e sendo até mesmo contrária à forma pela qual foi concebida pela tradição contemporânea a Schopenhauer, conhecida por idealismo alemão.

Recordemos o motivo fundador do Estado e o objetivo dessa instituição na letra do filósofo:

No Estado, portanto, reconhecemos o meio pelo qual o egoísmo, servindo-se da faculdade de razão, procura evitar as suas próprias consequências funestas que se voltam contra si, e, assim, cada um promove o bem-estar geral, porque dessa forma assegura o seu bem-estar particular. (SCHOPENHAUER, 2005: §62, 447; SCHOPENHAUER, 1911-1942: §62, I 413). ${ }^{16}$

${ }^{16}$ No original: „Wir haben also im Staat das Mittel kennen gelernt, wodurch 
Schopenhauer especula sobre como seria se fosse possível o Estado cumprir de forma plena seus objetivos, i.e., como seria se o Estado se realizasse de forma plena. A resposta que ele dá profere que cada vez mais seria possível dominar a natureza e, com isso, todo o mal seria extinto, instaurando-se, assim, algo parecido com um reino utópico. ${ }^{17}$ Mas, fugindo à utopia, nosso autor considera que, além do Estado sempre se encontrar distante de tal fim, mesmo se esse fosse alcançado, ainda nos restariam outros inumeráveis males e a vida manteria sua essência de sofrimento. $\mathrm{E}$, se os males fossem erradicados, o tédio ocuparia o lugar deles. $\mathrm{O}$ autor ressalta: as disputas e discórdias entre os indivíduos nunca são totalmente suprimidas pelo Estado. Mas, supondo que o Estado alcançasse plenamente o seu fim, que todos os males fossem superados, que os indivíduos vivessem em completa harmonia, qual seria o prognóstico de Schopenhauer? O denominado filósofo do pessimismo responde: "[...] o resultado seria a efetiva superpopulação de todo o planeta, cujo mal só uma imaginação audaciosa poderia agora tornar presente". (SCHOPENHAUER, 2005: §62, 447-448; SCHOPENHAUER, 1911-1942: §62, I 414). ${ }^{18}$

A especulação schopenhaueriana nos revela e apresenta interessantes fatos e indícios. A justiça temporal se produz no elemento mesmo do egoísmo, e pelo fato dela ser empírica, i.e., fenomênica, ela não pode ser mais que pura ilusão. As precauções contra o egoísmo não podem ser completamente eficazes porque elas são apenas aparência, elas não melhoram moralmente o ser, nem extirpam seus desejos em cometer injustiças. Tão logo a ameaça do castigo ou a promessa da recompensa sejam afastadas do indivíduo, os atos injustos já retornam à ordem do dia. Viver

der mit Vernunft ausgerüstete Egoismus seinen eigenen, sich gegen ihn selbst wendenden schlimmen Folgen auszuweichen sucht, und nun Jeder das Wohl Aller befördert, weil er sein eigenes mit darin begriffen sieht".

${ }^{17}$ Vale lembrar que para Schopenhauer a monarquia constitucional hereditária tripartida se aproxima da forma de governo mais perfeita.

${ }^{18}$ No original: „[...] das Resultat seyn, dessen entsetzliche Uebel sich jetzt nur eine kühne Einbildungskraft zu vergegenwärtigen vermag“. 
é tornar-se aquilo que se é, e o caráter egoísta é a mais frequente configuração da concreção da vontade num corpo. Nesse contexto, a justiça temporal não pode, dessa forma, ser plenamente realizável. Ela se realiza na medida em que também é um não alcance de seu fim último e pleno.

O Estado, enquanto organização do egoísmo coletivo, e o direito, enquanto forma pela qual se torna possível impor limites às manifestações desse egoísmo, não podem ser considerados o ultrapassamento desse egoísmo mesmo. Antes, são medidas de asseguramento da existência social, são a afirmação da diferença entre um indivíduo e o outro, um enredamento persistente no princípio de individuação; isso significa que viver no Estado é viver no seio do egoísmo coletivo organizado.

Conceitos como direito e moral, nucleares nesse ponto da argumentação do filósofo da vontade, só são passíveis de serem entendidos em sua totalidade quando colocados um em relação com o outro: a justiça temporal, i.e., a retaliação (Vergeltung), o Estado, seria o elemento relacional entre a moral - o conceito sempre positivo, que é referido ao ato, à parte ativa - e o direito - o conceito negativo, que é referido ao sofrer, à parte passiva. A justiça temporal seria o elo entre esses dois conceitos na medida em que relaciona o interior - a dimensão da experiência interna do indivíduo, o ser, o esse, o caráter, o sentimento de prática da injustiça - com o exterior - o agir, o operari, a motivação, o sentimento de sofrer injustiça. O conceito de consciência moral (Gewissen) mostra, aqui, sua centralidade ao possibilitar a delimitação e a articulação da doutrina pura do direito com a ciência política, permitindo a determinação da base teórica do Estado e do sistema penal, bem como o seu escopo, e a sua forma de atuação.

O Estado é, por sua vez, o elo entre os âmbitos da vontade e da representação, e intermedeia as relações entre os indivíduos no mundo empírico, assimilando e utilizando o reverso da pura doutrina do direito. Dessa forma, a doutrina do direito ocupa o status nucelar da ética schopenhaueriana, como a forma pela qual é possível conter as desvantajosas consequências da natureza egoísta humana. 
Contudo, a justiça temporal de alguma forma é falha: por depender das instituições humanas, por ser suscetível ao acaso e ao engano. Nesse aspecto ela pode ser considerada oposta à justiça eterna. Talvez, a passagem da justiça temporal para a justiça eterna possa ser entendida como a passagem do registro do direito para o registro da moralidade. Contudo, essa é uma outra questão, para um outro debate.

\section{Bibliografia}

CARTWRIGHT, D. Historical dictionary of Schopenhauer's philosophy. In: Historical dictionaries of religions, philosophies, and movements, n. 55; Oxford: Scarecrow Press, 2005.

FASSÒ. Historia de la filosofia del derecho v. II, tradução de José F. Lorca Navarrete. Madri: Ediciones Pirámide S.A., 1979.

GODART-VAN DER KROON, A. Schopenhauer's theory of justice and its implication to natural law. in: Jahrbuch der SchopenhauerGesellschaft 2003. Band 84. Frankfurt am Main: Verlag Köningshausen \& Neuman Würzburg, 2003, p. 121-145.

SCHOPENHAUER, A. Arthur Schopenhauers sämtliche Werke; hrsg. Von Paul Deussen. Munique: R. Piper, 1911-1942.

. The world as will and representation, 20 Tomo; Tradução E.F.J. Payne. Nova York: Dover Publications, 1966.

- Parerga and Paralipomena - Short philosophical essays; Translated from German by E. F. J. Payne - volume two. Oxford: Claredon Press, 2000.

. Metafísica de las costumbres; introdução, tradução e notas de Roberto Rodríguez Aramayo. In: Coleção Clássicos de la Cultura; Madri: Editorial Trotta SA, 2001.

. Sobre o fundamento da moral. Tradução Maria Lúcia Mello Oliveira Cacciola. São Paulo: Martins Fontes, 2001. 
$\mid 190$ |

O Lugar Sistematico da Doutrina...

O mundo como vontade e como representação, $1^{\text {o }}$ Tomo; Tradução, apresentação, notas e índices de Jair Barboza. São Paulo: Editora UNESP, 2005.

Recebido em 28/09/13.

Aprovado em 02/05/14 